\title{
Imipramine in the Treatment of Obsessive-Compulsive Symptoms in Schizophrenic Spectrum Illnesses: Three Case Reports
}

\author{
Ileana Zaharovits, M.D. \\ Maimonides Medical Center, Brooklyn, New York \\ Marvin H. Lipkowitz, M.D. \\ Maimonides Medical Center, Brooklyn, New York
}

Follow this and additional works at: https://jdc.jefferson.edu/jeffjpsychiatry

Part of the Psychiatry Commons

Let us know how access to this document benefits you

\section{Recommended Citation}

Zaharovits, M.D., Ileana and Lipkowitz, M.D., Marvin H. (1990) "Imipramine in the Treatment of ObsessiveCompulsive Symptoms in Schizophrenic Spectrum Illnesses: Three Case Reports," Jefferson Journal of Psychiatry. Vol. 8 : Iss. 1 , Article 7.

DOI: https://doi.org/10.29046/JJP.008.1.015

Available at: https://jdc.jefferson.edu/jeffjpsychiatry/vol8/iss1/7

This Article is brought to you for free and open access by the Jefferson Digital Commons. The Jefferson Digital Commons is a service of Thomas Jefferson University's Center for Teaching and Learning (CTL). The Commons is a showcase for Jefferson books and journals, peer-reviewed scholarly publications, unique historical collections from the University archives, and teaching tools. The Jefferson Digital Commons allows researchers and interested readers anywhere in the world to learn about and keep up to date with Jefferson scholarship. This article has been accepted for inclusion in Jefferson Journal of Psychiatry by an authorized administrator of the Jefferson Digital Commons. For more information, please contact: JeffersonDigitalCommons@jefferson.edu. 


\title{
Imipramine in the Treatment of Obsessive-Compulsive Symptoms in Schizophrenic Spectrum Illnesses: Three Case Reports
}

\author{
Ileana Zaharovits, M.D. \\ Marvin H. Lipkowitz, M.D.
}

\section{INTRODUCTION}

It has long been known that obsessions and compulsions occur during the course of a schizophrenic illness (1-7). It is, therefore, of interest that there has been little systematic research into the treatment of these symptoms in patients suffering from schizophrenia.

It is possible that the meager research in this area is related both to the difficulty at times in differentiating signs of a psychotic decompensation in severe obsessive-compulsive disorder (OCD) from those of schizophrenia; and to the significant amount of controversy regarding the function of obsessive compulsive symptoms in patients suffering from schizophrenia and related diseases. For example, Sullivan (3) was one of the first to note a relationship between schizophrenia and obsessive compulsive disorder, and maintained that these conditions can shift from one to the other. Over 30 years ago, Rosen (4) studied 30 obsessive schizophrenics and observed that the obsessions emerged either prior to, or concomitant with, the schizophrenic symptoms, and that none of the patients had received psychiatric treatment prior to the schizophrenic decompensation. The implication is that obsessions were not taken as seriously as the psychotic symptoms even though they had presaged serious illness. This is identical to one of the cases we will present.

Rosen's study was similar to several other early studies (5), indicating that the association between obsessive compulsive symptoms and schizophrenia is rather frequent, with percentages varying from $1 \%$ to $3.5 \%$, while more recent studies (8) tend to indicate that over $10 \%$ of the schizophrenic patients present significant obsessive-compulsive symptoms.

There has been significant controversy, over the function of obsessive symptoms in patients suffering from schizophrenia. In 1947, Stengel (9) suggested that obsessive compulsive phenomena might prevent personality disintegration in schizophrenic patients. Rosen (4) also referred to this association and observed that the duration, elaboration and variety of obsessions were inversely correlated with the severity of schizophrenic illness. In addition, he believed that 
the presence of affective symptoms represented a good prognostic sign in these patients. Twenty five years after Rosen published his article, Fenton and McGlashan (8) reported the results of their Chestnut Lodge follow-up study. Contrary to the previously held concepts, they concluded that obsessive compulsive symptoms represented a poor prognosis in schizophrenia. They compared the functioning of a group of obsessive schizophrenics to a control group of non-obsessive schizophrenics over a period of fifteen years, and observed significantly lower functioning and more frequent hospitalizations in the former group. Insel and Akiskal (10) explain this discrepancy as resulting from the difficulties in clinically differentiating schizophrenic symptoms from those of a psychotic decompensation in OCD. In fact, they felt that the earlier authors were at a disadvantage in lacking specific criteria such as those of DSM-III, as a result of which some of the patients described as schizophrenic with obsessive compulsive symptoms were in fact patients with severe OCD who had become psychotic following a transient loss of insight. They consider the progression of OCD into schizophrenia to be extremely rare, and that such a psychotic picture developing in a patient with OCD would be better classified as either a mood or a delusional disorder.

Several random clinical observations while working in a partial hospitalization unit tended to confirm the findings published by Fenton and McGlashan. Noting that some patients appeared to develop distressing obsessions and or compulsions in the early stages of a psychotic regression and that this invariably led to hospitalization, it was felt that an attempt to remove these symptoms by utilizing imipramine might prevent the hospitalization, and could result in no more serious harm than could be predicted if no treatment were attempted. The following case reports detail our experiences in this approach.

\section{CASE REPORTS}

\section{Case 1}

Mrs. A., a 32-year-old white female had previously been hospitalized on four occasions since age 16 , with the diagnosis of schizophrenia, paranoid type, characterized by persecutory delusions and, consisting of the belief that both the FBI and the Mafia were after her, auditory hallucinations of her grandmother's voice speaking to her. Her father also had been treated for the same condition. Each of her acute decompensations had been related to stressful events in her life (e.g. break-up of a love affair; birth of daughter; placement of daughter in foster care); each had been preceded by the onset of obsessive thoughts. These consisted of perfectionistic ideas which increasingly made it impossible for her to perform her daily routines, until finally she became completely immobilized. For example, prior to her first hospitalization she spent hours in the shower scrubbing her hands until they bled in an attempt to clean them "perfectly". Prior to the second hospitalization she failed her school exams because of her compulsion to study one topic in such detail that she was unable to cover an assigned area. At no time in the past were these treated as specifically obsessions and compulsions, but apparently were viewed 
as symptomatic expressions of the underlying schizophrenia. As a result, her only treatment consisted of neuroleptic medications (loxapine and trifluoperazine) to which she each time responded sufficiently to leave the hospital each time. However, she remained unemployed for many years, during several of which she lived in a residence for mentally disabled persons. At the time of the present episode, she was living with her boyfriend and her daughter, and attending the partial hospitalization program at our mental health center. After about a year in this program, she began to complain of the compulsion to spend most of her time in planning and making notes in preparation for her daily activities. Ultimately, she found herself unable to function, and grew increasingly anxious, fearing another psychotic decompensation and hospitalization. At the time she was receiving trifluoperazine $10 \mathrm{mg}$ h.s.; lorazepam $1 \mathrm{mg}$ bid prn; and benztropine 2 $\mathrm{mg}$ tid. We added imipramine to this regimen, rapidly increasing the dose to 100 $\mathrm{mg} /$ day. After one week of treatment, the patient noted a decrease in the severity of her compulsions, and after two weeks these symptoms had subsided almost completely with no evidence of deterioration in the schizophrenic picture. The patient remained stable for three months of follow-up after which she was discharged from the partial hospitalization program, on the medications described, with treatment continued in the outpatient clinic.

\section{Case 2}

Mrs. B., a 29-year-old divorced orthodox Jewish female had been hospitalized on four occasions with the diagnosis of schizoaffective disorder. Each of the admissions resulted from marked social withdrawal; disorganization of thoughts; paranoid delusions, and ultimately the complete inability to care for herself. Her first psychotic deterioration occurred soon after she married, after which she grew increasingly isolated from family and friends, and left her position as a kindergarden teacher. She began to develop the compulsion of hand washing after which she developed the delusion that her food was poisoned. In spite of this she did not receive any psychiatric intervention for approximately two years, when, following childbirth, her symptoms grew so incapacitating that she was taken to a psychiatrist who prescribed first clomipramine, and later an MAOI. However, she grew increasingly psychotic and required hospitalization. While in the hospital her acute symptoms were somewhat controlled by lithium and neuroleptics, but after discharge she was never able to return to her previous level of functioning, in spite of varied treatment efforts, including trials of carbamazepine and ECT. While the differential diagnosis from paranoid schizophrenia was a difficult one, it was felt that a diagnosis of schizoaffective disorder was more accurate.

Shortly after her fourth hospitalization, while a patient in our partial hospitalization service, she began again to demonstrate signs of withdrawal, developed a preoccupation with sexual thoughts and spent most of the time in her room at the residence in which she had lived for several years. She was unable to mobilize herself to attend the sessions of the partial hospitalization unit. She was then receiving a combination of lithium and a thiothixene which had produced slight improvement in her symptoms in the past. It appeared that repeat hospitalization was again imminent, and in the face of this we felt that a trial of imipramine was in order. This was added to her regimen, and rapidly increased to $150 \mathrm{mg} /$ day. In two weeks she noted some decrease in the severity of the sexual obsessions, and was able to resume her functioning in the partial hospitalization service. At three month follow-up, she demonstrated no signs of psychotic deterioration and continued to attend the day program in a regular fashion. 
Case 3

Mr. C., a 61-year-old married orthodox Jewish man was referred to our partial hospitalization program because of severe obsessions, compulsions, phobias, and hypochondriacal complaints which made it impossible for him to function. This man had never been hospitalized for psychiatric reasons, and had only one prior psychiatric contact, when, in his early twenties, he received outpatient therapy for several months, because of "problems in finding a job." Although he had obtained high grades in school, it remained difficult for him to find and keep a job, and for many years he worked in a very low-level position, retiring at age 50 because of a "heart condition." Although medically stable, he never returned to work. He married in his thirties (rather late for a man of his cultural background) explaining this as a result of his inability to support a family. At the time of his referral to the partial hospitalization service, he resided with his wife and two children. He had no other social contacts.

On admission to our service, the patient expressed concerns over cleanliness and orderliness, and feared becoming infected. He engaged in hand-washing rituals, feared contamination by touching a variety of objects in the house, and most specifically, feared that he had infected himself by "accidentally pulling a hair out of his anal area while taking a shower." He was quite anxious and appeared depressed. His speech was circumstantial and tangential but there was no evidence of acute psychosis. He had previously presented some sleep difficulties which were controlled by $5 \mathrm{mg}$ diazepam prescribed by his internist. He denied any suicidal ideations. There were insufficient indications for a diagnosis of major depressive disorder. MMPI testing was suggestive of a schizoid or schizotypal personality disorder, with a high score on the depressive scale. The final diagnosis was schizotypal personality disorder with obsessive compulsive symptoms.

He was treated for three months with supportive therapy in addition to the previously mentioned diazepam), with no improvement noted. At this time he was given imipramine, which was increased rapidly to $100 \mathrm{mg} /$ day. After approximately two weeks the patient noted a decrease in his obsessions and phobias. After one month the hand-washing rituals had disappeared, and the patient presented neither subjective complaints, nor any signs of obsessions or phobias. After four months, he was transferred to the outpatient clinic for continued supportive therapy in addition to the imipramine medication.

\section{DISCUSSION}

A survey of the literature reveals no systematic study of the effects of treating and removing obsessive compulsive symptoms which present in the course of a schizophrenic spectrum illness. There is even some controversy in the literature, with some authors claiming that these symptoms tend to prevent schizophrenic deterioration, and others noting that they tend to presage such deterioration. Although the most recent study (10) supported the latter position, there appears to be a reluctance on the part of clinicians to attempt to treat these symptoms with antidepressant medication. Perhaps this results from the concern that this medication might worsen the psychosis (11-15).

In this pilot study, three patients with schizophrenic spectrum illness who complained of severe obsessive compulsive symptoms were treated with imi- 
pramine in addition to their ongoing medication regimen. The imipramine was rapidly increased to $100-150 \mathrm{mg} /$ day. In each case, a noticeable improvement in the target symptoms was observed, with no psychotic deterioration occurring. In fact, in two of the patients the obsessive compulsive symptoms had in previous episodes served as signals of impending deterioration and hospitalization. In these two patients removal of the symptoms permitted a restoration of function, and the need for hospitalization was removed. All patients were followed for at least four months, and no recrudescence of symptoms or deterioration in functioning was noted. Imipramine was chosen because at the time of the study the tricyclic antidepressants, either alone or in combination with behavior therapy, provided the only widely accepted pharmacological approach to OCD (16-24). Subsequent to the completion of this study clomipramine became available in the United States. While fluoxetine was available, its efficacy in treating OCD was not yet widely known.

It should be noted that the introduction of DSM-III-R has made comparison of earlier studies with more recent ones more difficult, since many of the conditions originally considered to be schizophrenia have now been reclassified. In a rather broad way the concept of "schizophrenic spectrum" illnesses encompasses both the DSM-III-R classification of schizophrenia and present DSM-III$\mathrm{R}$ diagnoses which formerly were considered to be schizophrenia. This is the term used to identify the patients presented in the following. While only one of these met the DSM-III-R criteria for a diagnosis of schizophrenia, it is our opinion that the other two patients, one with a diagnosis of schizoaffective disorder, and the other with that of schizotypal personality disorder would each have been considered schizophrenic by the earlier authors quoted.

In spite of the positive results obtained, we still cannot state definitely that removal of obsessive compulsive symptoms in some schizophrenics might not lead to deterioration. Neither can we state with certainty that the addition of imipramine to ongoing neuroleptic medications will regularly lead to the alleviation of these symptoms. However, given the positive results of this pilot clinical study, the authors are planning a structured research program in hopes of resolving remaining controversies in this area.

\section{REFERENCES}

1. Parkin A: Neurosis and schizophrenia: II. Modern Perspectives. Psychiat Quart 40:217-235, 1966

2. Birnie WA, Litman SK: Obsessionality and schizophrenia. Can Psychiatr Assoc J 23:77-81, 1978

3. Sullivan HS: Clinical Studies in Psychiatry. New York, W.W. Norton and Company, 1956

4. Rosen I: The Clinical significance of obsessions in schizophrenia. J Ment Sci 103:773785,1957

5. Jahrreiss W: Obsessions during schizophrenia. Archieve fur Psychiatrie 77:740-788, 1926 
6. Jenike MA, Baer L, Minichiello WE, et al: Coexistent obsessive compulsive disorder and schizotypal personality disorder: A poor prognostic indicator. Arch Gen Psychiatry $43: 296,1986$

7. Jenike MA, Baer L, Minichiello WE, et al: Concomitant obsessive compulsive disorder and schizotypal personality disorder. Am J Psychiatry 143:530-532, 1986

8. Fenton WS, McGlashan TH: The prognostic significance of obsessive compulsive symptoms in schizophrenia. Am J Psychiatry 143:437-441, 1986

9. Stengel EA: Study on some clinical aspects of the relationship between obsessional neurosis reaction types. J Ment Sci 91:166-187, 1945

10. Insel TR, Akiskal HS: Obsessive compulsive disorder with psychotic features: A phenomenologic analysis. Am J Psychiatry 143:1527-1533, 1986

11. Baldessarini RJ: Chemotherapy in Psychiatry, Principles and Practice. Cambridge, Harvard University Press, 1985

12. Nelson JG, Bowers M, Sweeney DR: Exacerbation of psychosis by tricyclic antidepressants in delusional depression. Am J Psychiatry 136:574-576, 1979

13. Siris SG, Van Kammer DP, Docherty JP: Use of antidepressant drugs in schizophrenia. Arch Gen Psychiatry 35:1368-1377, 1978

14. Prusoff BA, Williams DH, Weissman MM, et al: Treatment of secondary depression in schizophrenia. A double-blind, placebo-controlled trial of amitriptyline added to perphenazine. Arch Gen Psychiatry 36:569-575, 1979

15. Kramer MS, Vogel WH, DiJohnson C, et al: Antidepressants in 'depressed' schizophrenic inpatients. Arch Gen Psychiatry 46:922-928, 1989

16. Marks IM, Hodgson R, Rachman S: Treatment of chronic obsessive compulsive neurosis by in-vivo exposure: A two-year follow-up and issues in treatment. Brit J Psychiat 143:349-364, 1975

17. Marks IM, Stern RS, Mawson D, et al: Clomipramine and exposure for obsessive compulsive rituals: I. Brit J Psychiat 136:1-25, 1980

18. Marks I: Are there anticompulsive or antiphobic drugs? Review of evidence. 1983; Brit J Psychiat 143:338-347, 1983

19. Lelliot PT, Monteiro WO: Drug treatment of obsessive compulsive disorders. Drugs 31:75-80, 1986

20. Insel TR, Murphy DL, Cohen RM, et al: Obsessive compulsive disorder, a double blind trial of clomipramine and clorgyline. Arch of Gen Psychiatry 40:605-612, 1983

21. Sartory G: Benzodiazepines and behavioural treatment of phobic anxiety. Behavioural Psychotherapy 11:204-217, 1983

22. White K, Keck PE, Lipinski J: Serotonin-uptake inhibitors in obsessive compulsive disorder. A case report. Comprehensive Psychiatry 27:211-214, 1986

23. Mavissakalian M, Turner S, Michelson L, et al: Tricyclic antidepressants in obsessivecompulsive disorder: Antiobsessional or antidepressant agents? II. Am J Psychiatry $142: 572-576,1985$

24. Mellman LA, Gorman JM: Successful treatment of obsessive-compulsive disorder with ECT. Am J Psychiatry 141:596-597, 1984 